\title{
KEUTAMAAN YAJNA DI JAMAN KALIYUGA \\ (PERSPEKTIF MANAVADHARMASASTRA) \\ Oleh
}

\section{Gelar Sumbogo Peni}

Era sekarang dengan semakin cepatnya informasi disemua lini kehidupan, juga berdampak terhadap kehidupan beragama, kegiatan yadnya salah satu yang nampak. Unsur-unsur alami pada sarana dan prasarana Yadnya mulai bergeser kearah yang praktis dan instan. Kehidupan sosial "gotong royong” berubah menjadi individualisme. Memberikan punia (berderma) bukan semata-mata atas dasar tulus iklas, tetapi mempunyai motif atau kepentingan. Jaman sekarang bukan lagi tanpa pamrih, justru melakukan sesuatu pasti ada pamrih.

Atas dasar pergeseran dan perubahan perilaku itulah, hendaknya kita sebagai makhluk ciptaan-Nya dalam melakukan kegiatan-kegiatan yang sejalan dengan ajaran agama dan sesuai perintah dari Tuhan. Pengabdian adalah jalan yang mudah untuk memperoleh kebijaksanaan. Pengabdian adalah salah satu bentuk ekstraksi dari pengetahuan dan pengalaman spiritual yang tinggi.

Manavadharmasastra merupakan sebuah kitab Dharma yang dihimpun dalam bentuk sistematis oleh Bhagawan Bhrgu, salah seorang penganut ajaran Manu. Kitab ini dianggap paling penting bagi masyarakat Hindu dan dikenal sebagai salah satu dari kitab Sad Wedangga. Wedangga adalah kitab yang merupakan batang tubuh Weda yang tidak dapat dipisahkan dengan Weda Sruti dan Weda Smrti.

Dalam ajaran agama Hindu, Yuga atau Mahayuga adalah suatu siklus perkembangan zaman yang terjadi di muka bumi, yang terbagi menjadi empat zaman, yaitu Satyayuga atau Kerta Yuga, Tretayuga, Dwaparayuga, dan Kaliyuga.

Menurut Manawa Dharmasastra 1.86 sebagaimana dikutip diawal tulisan ini, prioritas beragama-pun menjadi berbeda-beda pada setiap zaman. Pada zaman Kerta Yuga, kehidupan beragama diprioritaskan dengan cara bertapa. Pada Treta Yuga dengan memfokuskan pada jnyana. Pada zaman Dwapara Yuga dengan upacara yadnya dan pada zaman Kali Yuga beragama dengan prioritas melakukan dana punia.

Kata Kunci : Yajna, Manavadharmasastra, Yuga, Kaliyuga

A. Pendahuluan 
Perkembangan serta percepatan informasi disegala lini kehidupan masyarakat yang sudah tidak terbendung lagi, menimbulkan berbagai konsekwensi. Sebagai salah satu dari dampak cepatnya akses komunikasi dan informasi, menghasilkan suatu pergeseran pola hidup dimasyarakat, baik kehidupan masyarakat dibidang sosial, ekonomi, budaya, politik dan lain sebagainya. Selain dampak positif atau yang menguntungkan dirasakan oleh khalayak umum, juga tentunya dimbangi oleh dampak yang merugikan pula bagi sebagian masyarakat.

Pergeseran, juga ada dijumpai dalam kehidupan kita sebagai umat beragama dalam hal tertentu. Ketika era masih belum secanggih sekarang, kehidupan beragama khususnya agama Hindu, umat Hindu ketika melaksanakan yadnya tentu menggunakan sarana dan prasarana yang serba alami, dikerjakan dengan gotong royong. melakukan segala macam upaya untuk dapat berbakti kepada Tuhan dengan dasar tulus iklas.

Hal ini kita lakukan sebagai wujud syukur kita atas segala kemurahan, kenikmatan dan ungkapan rasa syukur kita atas segala yang telah diberikan oleh Sang Hyang Widhi Wasa/Ranying Hatala Langit. Tuhan mengatakan dalam Gita "Siapa yang terus menerus mengingat Aku, sangat Kucintai. Karena itu, ingatlah Aku selalu. Persembahkan kepada-Ku pikiran dan akal budimu. Serahkanlah segala-galanya kepada-Ku. Maka engkau pasti akan mencapai Aku."

Di Era sekarang pergeseran juga mewarnai dibidang kehidupan beragama, kegiatan yadnya salah satu yang nampak. Unsur-unsur alami pada sarana dan prasarana Yadnya mulai bergeser kearah yang praktis dan instan. Kehidupan sosial "gotong royong" berubah menjadi individualisme. Memberikan punia (berderma) bukan sematamata atas dasar tulus iklas, tetapi mempunyai motif atau kepentingan. Era sekarang bukan lagi tanpa pamrih, justru melakukan sesuatu pasti ada pamrih.

Atas dasar pergeseran dan perubahan perilaku itulah, hendaknya kita sebagai makhluk ciptaan-Nya dalam melakukan kegiatan-kegiatan yang sejalan dengan ajaran agama dan sesuai perintah dari Tuhan. Pengabdian adalah jalan yang mudah untuk memperoleh kebijaksanaan. Pengabdian adalah salah satu bentuk ekstraksi dari pengetahuan dan pengalaman spiritual yang tinggi.

Ada banyak jalan yang dapat kita lakukan untuk mengabdikan hidup kita kepada Tuhan Yang Maha Esa. Banyak juga kitab-kitab suci yang menyatakan kewajiban kita untuk berbakti dan mengabdi kehadapan Tuhan Yang Maha Esa. Wujud 
dan prioritas bentuk pengabdian diri yang dilakukan, mempunyai porsi di masingmasing zaman dalam Mahayuga yang berbeda.

\section{B Kitab Suci Manavadharmasastra}

Kitab suci Manavadharmasastra merupakan salah satu kitab Dharma yang dihimpun secara sistematis oleh Bhagawan Bhrgu, salah seorang penganut ajaran Manu. Nama otoritas kitab dharmasastra ini disebut Manu dan dari nama itulah lahirnya nama Dharmasastra. Seluruh ajaran dalam kitab ini dianggap memuat ajaran Bhagawan Manu. Bhagawan Bhrgu penerima ajaran Manu, adalah salah seorang dari Sapta Maharsi, yang berhasil dan mampu menghimpun dan mensistematisir ajaran itu di jamannya.

Kitab suci Manavadharmasastra ini dianggap penting dan menarik dari sekian banyak kitab-kitab sastra yang memuat himpunan pokok ajaran Hindu dan dikenal sebagai salah satu dari kitab Wedangga. Wedangga adalah kitab weda yang merupakan bagian batang tubuh dari Weda. Dharmasastra merupakan salah satu dari Sad Wedangga dan mempunyai arti serta kedudukan penting dalam masyarakat Hindu. Adapun yang dimaksud dengan Sad Wedangga (enam batang tubuh Weda) yaitu Siksa, Vyakarana, Chanda, Nirukta, Jyotisa dan Kalpa.

Jenis Vedangga terpenting dan ber hubungan dengan kitab Manavadharmasastra ini adalah jenis Kalpa. Asal usul kitab Kalpa ini bersumber pada Brahmana Samhita dan ditulis dalam bentuk sutra atau sloka. Isinya berkisar pada ajaran-ajaran keagamaan dan merupakan kitab pedoman (peraturan hidup) bagi umat Hindu dalam kehidupan mereka sehari-hari. berdasarkan penggunaannya, kelompok Kalpa vedangga ini terdiri atas empat jenis menurut topiknya sendiri-sendiri. Keempat kelompok itu ialah :

a. Srauta-sutra, (Panduan untuk upacara besar)

b. Grhya-sutra, (Panduan untuk orang berumah tangga)

c. Dharma-sutra, (Panduan untuk melakukan pemerintahan)

d. Sulva-sutra, (Panduan untuk membuat bangun-bangunan agama)

Penafsiran terhadap sloka-sloka pada Kitab Manawa Dharmasastra diperkirakan telah dimulai sejak tahun $120 \mathrm{M}$ dipelopori oleh Kullukabhatta dan Medhiti di tahun 825 M. Kemudian beberapa Maha Rsi memasyarakatkan tafsir-tafsir Manawa Dharmasastra menurut versinya masing-masing sehingga menumbuhkan beberapa aliran Hukum Hindu, misalnya: Yajnawalkya, Mitaksara, dan Dayabhaga. 
Para Maha Rsi yang melakukan penafsiran-penafsiran pada Manawa Dharmasastra menyesuaikan dengan tradisi dan kondisi setempat. Aliran yang berkembang di Indonesia adalah Mitaksara dan Dayabhaga.

Di zaman Majapahit, Manawa Dharmasastra lebih populer disebut sebagai Manupadesa. Proses penyesuaian kaidah-kaidah hukum Hindu nampaknya berjalan terus hingga abad ke-12 dipelopori oleh tokoh-tokoh suci: Wiswarupa, Balakrida, Wijnaneswara, dan Apararka.

Dua tokoh pemikir Hindu, yaitu Sankhalikhita dan Wikhana berpandangan bahwa Kitab Manawa Dharmasastra adalah ajaran dharma yang khas untuk zaman Krtayuga, sedangkan sekarang adalah zaman Kaliyuga. Keduanya mengelompokkan dharmasastra yang dipandang sesuai dengan zaman masing-masing, yaitu:

a. Manawa Dharmasastra sesuai untuk zaman Krta Yuga

b. Gautama Dharmasastra sesuai untuk zaman Treta Yuga

c. Samkhalikhita Dharmasastra sesuai untuk zaman Dwapara Yuga

d. Parasara Dharmasastra sesuai untuk zaman Kali Yuga

Dari temuan-temuan di atas dapatlah diartikan bahwa ajaran Manu atau Manawa Dharmasastra tidaklah dapat diaplikasikan begitu saja tanpa mempertimbangkan kondisi, waktu, dan tempat (desa-kala-patra).

\section{Yuga}

Dalam ajaran agama Hindu, Yuga atau Mahayuga adalah suatu siklus atau fase perkembangan zaman yang terjadi di muka bumi, yang terbagi menjadi empat zaman, yaitu Satyayuga atau Kerta Yuga, Tretayuga, Dwaparayuga, dan Kaliyuga. Menurut ajaran Hindu, keempat zaman tersebut membentuk suatu siklus, sama seperti siklus empat musim. Siklus tersebut diawali dengan Satyayuga menuju Kaliyuga.

Setelah Kaliyuga berakhir, maka akan kembali ke jaman Satyayuga yang baru. Perubahan zaman dari Satyayuga (zaman keemasan) menuju Kaliyuga (zaman kegelapan) merupakan kenyataan bahwa ajaran kebenaran dan kesadaran sebagai umat beragama lambat laun akan berkurang, seiring bertambahnya jumlah umat manusia dan perubahan zaman. Dimana pada akhirnya manusia akan merasa bahwa di suatu masa yang sudah tua, ketika bumi renta, ketika kerusakan moral dan pergeseran budaya sudah bertambah parah, maka sudah tiba saatnya untuk memulai ke fase jaman baru lagi. 
Jika diibaratkan seperti Lembu Dharma (simbol perkembangan moralitas), keempat siklus Yuga (Caturyuga) seperti lembu yang berdiri dengan empat kakinya, dimana setiap zaman berganti, kaki lembu juga ikut berkurang satu, simbol moralitas yang berkurang setiap zaman. Zaman Satyayuga seperti lembu yang berdiri dengan empat kaki, moralitas dan nilai-nilai kemanusiaan sangat dijunjung tinggi. Sedangkan zaman Tretayuga seperti lembu yang berdiri dengan tiga kaki. Masa Dwaparayuga dengan dua kaki, dan masa Kali Yuga hanya dengan satu kaki. Pada zaman itu, nilainilai moralitas, kemanusiaan, kebenaran tidak bisa berdiri lagi dengan stabil.

Siklus tersebut dimulai dari zaman keemasan (Satyayuga), dan diakhiri oleh zaman kegelapan (Kaliyuga). Setelah zaman kegelapan berakhir, dimulailah zaman keemasan yang baru. Ketika masa kegelapan berakhir, maka zaman baru akan muncul, dimana manusia-manusia yang memiliki sifat jahat sudah dibinasakan sebelumnya untuk memulai kehidupan baru yang lebih damai. Itulah siklus masa dari Satyayuga menuju Kaliyuga, dan Kaliyuga akan kembali kepada Satyayuga. Periode dari Satyayuga menuju Kaliyuga disebut 1 Mahayuga. Setelah Mahayuga berlangsung selama 71 kali, maka tercapailah suatu periode yang disebut Manwantara. Setelah 14 Manwantara berlangsung, maka dicapailah suatu periode yang disebut Kalpa. Menurut ajaran Hindu, pada saat periode tersebut dicapai, maka alam semesta dihancurkan.

Menurut pengamatan beberapa para ahli juga bersumber dari sastra-sastra agama yang pernah mereka baca, sesungguhnya manusialah yang menyebabkan zaman itu berganti. Perilaku manusia juga sebagai sebagai indikator kapan zaman Kaliyuga itu datang, kapan dia akan berakhir dan kapan jaman Kerta itu akan datang.

\section{Karakter Setiap Zaman}

1. Kertayuga

Satyayuga atau Kertayuga, merupakan tahap awal dari empat (catur) Yuga. Siklus Yuga merupakan siklus yang berputar seperti roda. Setelah Satyayuga berakhir, untuk sekian lamanya kembali lagi kepada Satyayuga. Satyayuga berlangsung kurang lebih selama 1.700.000 tahun.

Masa kerta yuga adalah merupakan masa yang penuh kedamaian dimana pada masa tersebut tidak ada manusia yang berbuat adharma walaupun hanya dalam pikiran. Manusia pada masa itu selalu mematuhi ajaran-ajaran kebenaran dan tiada pernah menyakiti mahluk lain baik dalam pikiran, perkataan maupun perbuatan. 
Yang ada dalam kehidupan manusia pada masa tersebut adalah : berbuat untuk kesenangan orang lain dan berjalan diatas jalannya dharma sehingga jaman tersebut sering juga dinamakan: Zaman Satya Yuga yang mengandung arti bahwa pada masa itu manusia hidup didalam kesetiaan.

Satyayuga merupakan zaman keemasan, ketika orang-orang sangat dekat dengan Tuhan. Hampir tidak ada kejahatan. Pelajaran agama dan meditasi (mengheningkan pikiran) merupakan sesuatu yang sangat penting pada zaman ini. Konon rata-rata umur umat manusia bisa mencapai 4.000 tahun ketika hidup di zaman ini. Menurut Nathashastra, di masa Satya Yuga tidak ada Natyam karena pada masa itu semua orang berbahagia.

Pada masa Satyayuga, orang-orang tidak perlu menulis kitab, sebab orangorang dapat berhubungan langsung dengan Yang Maha Kuasa. Pada masa tersebut, tempat memuja Tuhan tidak diperlukan, sebab orang-orang sudah dapat merasakan di mana-mana ada Tuhan, sehingga pemujaan dapat dilakukan kapanpun dan di manapun.

Pada masa Satyayuga, kesadaran umat manusia akan Dharma (kebenaran, kebajikan, kejujuran) sangat tinggi. Budaya manusia sangat luhur. Moral manusia tidak rusak. Kebenaran sangat dijunjung tinggi sebagai aturan hidup. Hampir tidak ada kejahatan dan tindakan yang melanggar aturan. Maka dari itu, zaman tersebut disebut juga 'zaman keemasan'.

2. Tretayuga

Masa Tretayuga merupakan zaman kerohanian. Sifat-sifat kerohanian sangat jelas tampak. Agama menjadi dasar hidup. Meskipun begitu, orang-orang mulai berbuat dosa dan penjahat-penjahat mulai bermunculan. Namun semua masih berjalan seimbang. Aktivitas yang berhubungan dengan agama dan kerohanian terjadi dimana-mana dan sangat erat dengan kehidupan manusia. Pada zaman ini muncul berbagai peristiwa. Peristiwa yang paling terkenal adalah munculnya AwataraWisnu yang kelima, keenam, dan kedelapan, yakni: Wamana, Parasurama, dan Rama. Pada zaman ini, seseorang yang pandai, memiliki pengetahuan dan wawasan luas, serta ahli filsafat akan sangat dihormati.

3. Dwaparayuga 
Zaman ini berlangsung selama 864.000 tahun. Merujuk pada apa yang tertulis di dalam Purana, zaman Dwaparayuga berakhir di kala Kresna kembali ke kediaman abadinya di Waikuntha. Pada masa Dwaparayuga, manusia mulai bertindak rasional. Penjahat-penjahat dan orang-orang berdosa bertambah. Kelicikan dan kebohongan mulai tampak. Yang diutamakan pada zaman ini adalah pelaksanaan ritual. Asalkan mampu melaksanakan upacara, maka seseorang akan dihormati. Akhir zaman Dwapara dimulai ketika Kresna meninggal, setelah itu dunia memulai zaman terakhir, Kali Yuga.

4. Kaliyuga

Zaman kaliyuga merupakan zaman kehancuran. Banyak manusia mulai melupakan Tuhan. Banyak moral manusia yang rusak parah. Kaum pria banyak berkuasa dan wanita dianggap sebagai objek pemikat nafsu mereka. Banyak siswa berani melawan gurunya. Banyak orang-orang yang mencari nafkah dengan tidak jujur. Dan banyak lagi kepalsuan, kebohongan, kejahatan, dan tindak kekerasan. Pada zaman ini, uang yang paling berkuasa. Hukum dan jabatan mampu dibeli dengan uang. Sekarang ini banyak para pemuka agama yang belum melaksanakan swadharmaningnya dengan benar. Ada kecenderungan posisi tokoh agama menjadi semacam komuditas bermotif ekonomi atau politik.

\section{E. Preoritas Ritual Agama Menurut Manavadharmasastra}

Titik berat pelaksanaan aktivitas ritual menurut ajaran Hindu, dipengaruhi oleh periode yuga itu sendiri. Dimana setiap periode yuga, titik berat pelaksanaan yadnya tidaklah sama, seperti pada sloka berikut ini :

Tapah pararn kerta yuge tretayam jnyanamucyate dwapare yajnyawaewahur danamekam kalau yuge

\section{(Manawa Dharmasastra, I.86)}

Artinya: Bertapa prioritas beragama zaman Kerta Yuga, prioritas beragama zaman Treta Yuga dalam jnyana (pengetahuan), zaman Dwapara Yuga dengan upacara yadnya (Kurban Suci), sedangkan prioritas beragama zaman Kali Yuga adalah Dana Punia (bersedekah). 
Ada lima hal yang wajib dijadikan dasar pertimbangan untuk mengamalkan agama (dharma) agar sukses (Dharmasiddhiyartha). Hal itu dinyatakan dalam Manawa Dharmasastra VII.10. Lima dasar pertimbangan itu adalah iksha, sakti, desa kala dan tattwa. Iksha adalah pandangan hidup masyarakat setempat, sakti adalah kemampuan, desa adalah aturan rohani setempat, kala (waktu) dan tattwa (hakikat kebenaran Weda).

Kala sebagai salah satu hal yang wajib dipertimbangkan dalam mengamalkan agama Hindu. Waktu dalam ajaran Hindu memiliki dimensi amat luas. Ada waktu dilihat dari konsep Tri Guna. Karena itu ada waktu satvika kala, rajasika kala dan tamasika kala. Ada waktu berdasarkan konsep Yuga - Kerta Yuga, Treta Yuga, Dwapara Yuga dan Kali Yuga. Keadaan zaman ditiap-tiap yuga itu berbeda-beda. Karena itu, prioritas ritual beragama-pun berbeda-beda pada setiap zaman.

1 Keutamaan bertapa di zaman Kertayuga

Pada zaman Kertayuga kegiatan beragama diprioritaskan atau dititik beratkan dengan melaksanakan tapa atau semadhi. Pada zaman Kertayuga, pikiran orang umumnya murni. Mereka tidak terlalu memprioritaskan keterikatan pikiran pada kehidupan duniawi. Situasi pada periode itu juga sangat mendukung, hal-hal yang bernuansa modernisasi masih belum ada. Oleh karena itu bertapa atau bermeditasi mudah dan wajar bagi mereka. Itulah sebabnya pengendalian pikiran tidak terlalu susah untuk dilakukan bagi orang-orang

Kegiatan bertapa yang dimaksud ialah usaha sadar untuk melakukan pengekangan diri dengan yoga dan semadhi. Istilah tapa diambil dari bahasa Sansakerta, yang bermakna olah batin dengan mengasingkan diri dari keramaian dunia serta menahan hawa nafsu.

Bertapa sama artinya dengan melakukan bakti kepada Sang Hyang Widhi Wasa/Ranying Hatall Langit, dengan bertapa semua keterikatan pikiran pada halhalyang bersifat keduniawian dapat dikontrol dan dikendalikan oleh pikiran. Dengan melakukan tapa orang yang hidup di zaman Kerta Yuga menjalani kehidupan beragamanya. Sebab dengan bertapa mereka dapat menjaga pikirannya agar seimbang dan tidak mudah mengumbar nafsu indriawinya kepada hal-hal yang buruk dan bertentangan dengan sastra agama. 
Maka tidak disangsikan lagi bila zaman Kertayuga disebut sebagai zaman keemasan. Sebab kesadaran umat manusia akan Dharma (kebenaran, kebajikan, kejujuran) pada zaman itu sangat tinggi. Budaya manusia sangat luhur. Moral manusia tidak rusak. Kebenaran sangat dijunjung tinggi sebagai aturan hidup. Hampir tidak ada kejahatan dan tindakan yang melanggar aturan.

2. Keutamaan Jnana di Zaman Tertayuga

Pada zaman Tertayuga, ada perwujudan Awatara dan orang-orang secara mudah dapat memuja langsung pada Tuhan. Oleh karena itu pemujaan dinyatakan sebagai bentuk prinsip Sadhana pada masa itu. Pada zaman Tertayuga kebahagiaan abadi dicapai melalui pengetahuan tentang Brahman. Pelepasan dicapai melalui realisasi identitas dari roh pribadi dengan roh tertinggi atau Brahman. Penyebab keterikatan dan penderitaan adalah awidya atau ketidaktahuan. Jiwa kecil, karena ketidaktahuannya secara mudah menggambarkan dirinya terpisah dari Brahman. Awidya bertindak seperti tirai atau layar dan menyelubungi Jiwa dari kebenaran yang sesungguhnya. Pengetahuan tentang Brahman atau Brahman Jnana membuka selubung ini dan membuat Jiwa bersandar pada Sat Cit Ananda Swarupa (sifat utamanya sebagai keberadaan kesadaran kebahagiaan mutlak) dirinya.

Penguasaan atasJnana atau budi pekerti adalah pelunasan segala penderitaan. Penderitaan adalah kondisi mental seseorang yang timbul dari identifikasi diri yang salah dari atma pada badan jasmaninya. Ini disebut dehatmabuddhi. Jiwa sejati seseorang adalah kenyataan yang permanen dan kekal abadi dari sifatnya. Ini disebut atman. Ini adalah "aku" seorang manusia. Setelah mencapai tujuan kesadaran bersatu dengan Brahman (kebahagiaan abadi) yang teragung ini, maka tidak ada lagi yang dipikirkan lebih tinggi dari itu. Inilah tingkat tertinggi dari budi pekerti jnana. Orang yang mencapai ini adalah seorang jnani sejati. Seorang jnani demikian tidak akan tergoyahkan oleh penderitaan yang paling dalam sekalipun. Ini telah diyakinkan oleh Sri Krisna dalam Bhagavadgita VI. 22:

yam labdhacha aparam labham

manyate nadhikam tatah

yasminsthitho na duhkena

guruna pi vichalyate

Artinya: 
'Dimana tercapai apa yang dipikirkan

dan tiada lagi lebih mulia di luar itu

yang dapat dicapai, di sana ia tertuju

tiada tergoyahkan oleh duka terberat sekalipun’

Jnana bukan hanya pengetahuan kecerdasan, mendengarkan atau membenarkan. Ia bukan hanya persetujuan kecerdasan, tetapi realisasi langsung dari kesatuan atau penyatuan dengan Yang Tertinggi yang merupakan para widya.

3. Keutamaan Yadnya di Zaman Dwaparayuga

Pada fase zaman Dwaparayuga kegiatan ritual agama dititik beratkan dengan melaksanakan yadnya (Kurban Suci). Pada zaman Dwaparayuga bahanbahan untuk melakukan yadnya atau pengorbanan dapat diperoleh secara mudah. Orang-orang memiliki kecenderungan aktif. Oleh karena itu mudah bagi mereka untuk melaksanakan upacara Agnihotra, Jyotistoma, Darsa-Paurnima dan yadnyayadnya lainnya.

Ada lima upacara kurban harian besar yang harus dilaksanakan oleh setiap kepala keluarga, yaitu, 1. Brahma Yajna, yang disebut juga Weda Yajna, yaitu kurban kepada Brahman atau kitab suci Weda, atau para orang suci; 2. Dewa Yajna, kurban kepada para Dewa; 3. Pitr Yajna, kurban kepada para leluhur; 4. Bhuta Yajna, kurban kepada semua makhluk; 5. Manusya Yajna, kurban kepada sesama manusia. Pelaksanaan kelima yajna ini berguna untuk rotasi atau pendakian spiritual seseorang. Dengan melaksanakan ritual tersebut, seseorang akan mendapatkan pengetahuan dan kesadaran, dengan mempelajari kitab-kitab suci yang ditulis oleh para $r s i$ agung. Ia mendapat bantuan dari teman-teman, kerabat dan keluarganya. Orang tuanya memberinya badan fisik yang dihidupi oleh susu sapi, nasi, sayur-mayur dan buah-buahan. Kelima unsur membantunya dan ia tak dapat hidup tanpa oksigen dan air. Para Dewa dan Pitr memberkahinya. Oleh karena itu, ia berhutang lima macam kepada alam semesta ini, dan harus membayarnya kembali dengan melaksanakan kelima upacara kurban harian ini.

Mengajarkan dan belajar kitab suci, merupakan Rsi Yajna; Tarpana atau persembahan air pada arwah leluhur dan upacara sraddha, merupakan Pitr Yajna; Homa atau persembahan kepada api, merupakan Dewa Yajna; Persembahan makanan kepada semua makhluk ciptaan, merupakan Bhuta Yajna. 
Dengan melakukan kegiatan-kegiatan kemanusiaan sehari-hari dan simpati, manusia mengembangkan sifat welas asih dan melenyapkan kebencian. Keakuan, hati yang kaku secara perlahan-lahan dapat dilembutkan, dan ia mengusahakan kasih sayang universal. Ia mencoba untuk merasakan kesatuannya dengan semua makhluk, dan perasaannya yang dahulu terpisah disebabkan keakuan dan egoism, secara perlahan-lahan berkurang dan akhirnya lenyap. Keseluruhan kehidupannya hendaknya dijadikan kehidupan pengorbanan dan kewajiban.

4. Keutamaan Dana Punia di Zaman Kaliyuga

Zaman Kaliyuga banyak mendapatkan gangguan pada pikirannya, dengan hilangnya kaki-kaki penyangga Dharma maka kita kurang memiliki kekuatan kehendak dan daya penalaran atau penyelidikan rasional. Sangat sulit untuk memperoleh bahan-bahan untuk melakukan upacara kurban, karena ekosistem dunia sudah mulai terganggu. Selain itu, orang-orang di zaman Kaliyuga disibukkan oleh pekerjaan mereka demi mengejar materi sebanyak-banyaknya. Oleh karena itu, untuk menerapkan ajaran agama kebanyakan mereka melakukan dana punia agar lebih cepat dan instan.

Dana punia menurutHindu merupakan salah satu ajaran yang harus dihayati dan diamalkan. Pengertian dana punia adalah pemberian yang baik dan suci dengan tulus ikhlas sebagai salah satu bentuk pengamalan ajaran dharma. Sesuai dengan asal kata dana punia, dana berarti pemberian dan punia berarti selamat, baik, bahagia, indah dan suci. Dana punia merupakan suatu sarana untuk meningkatkan sradha dan bhakti kita kepada Sang Hyang Widhi Wasa, selain itu dengan berdana punia akan membangun sikap kepedulian kita terhadap sesama.

Ajaran dana punia dilandasi oleh ajaran Tattvam Asi, yang berarti aku adalah kamu, kamu adalah aku, kita semua adalah sama. Pandanglah setiap orang seperti diri kita sendiri yang memerlukan pertolongan, bantuan atau perlindungan untuk mewujudkan kebahagiaaan hidup yang sejati, seperti diamanatkan dalam kitab suci Veda, "vasudhaivakutumbakam" semua makhluk adalah bersaudara. Manusia merupakan makluk sosial dalam arti manusia tidak dapat hidup sendiri sehingga memerlukan bantuan orang lain. 
Dalam Kitab Manawadharmasastra berisi tentang Hukum Hindu, termasuk didalamnya menjelaskan tentang dana punia. Dalam kitab Manavadharmasastra, terkandung ajaran yang menjelaskan tentang dana punia, sebagai berikut :

" caktito'pacamanebhyo data-wyam grha medhina,

samwaibhagasca bhutebhyah kartawyo'nuparodhatah "

artinya :

"Seorang kepala keluarga harus memberi makan sesuai kemampuannya kepada mereka yang tidak menanak dengan sendirinya (yaitu pelajar dan pertapa) dan kepada semua makhluk. Seseorang hendaknya membagi-bagikan makanan tanpa mengganggu kepentingannya sendiri". (Manawadharmasastra IV.32).

" triswapye tesu dattam hi widhina apyarjitam dhanam,

datur bhawatyan arthaya paratra daturewa ca"

artinya :

"Walaupun harta itu diperoleh sesuai menurut hukum (dharrna) tetapi bila tidak didermakan (disedekahkan/diamalkan) kepada yang layak, akan terbenam ke kawah neraka”. (Manawadharmasastra IV. 193).

" sraddhayestam ca purtam ca

nityam kuryada tandritah,

craddhakrite hyaksaye te

bhawatah swagatairdhanaih "

artinya :

"Hendaknya tidak jemu-jemunya ia berdana punia dengan memberikan hartanya dan mempersembahkan sesajen dengan penuh keyakinan. Memperoleh harta dengan cara yang benar dan didermakan akan memperoleh tempat tertinggi (Moksa)". (Manawadharmasastra IV.226).

" yatkimcidapi data wyam yacitenanasuyaya,

utpatsyate hi tatpatram yattarayati sarwatah "

artinya :

"Apabila dimintai, hendaknya ia selalu memberikan sesuatu, walaupun kecil jumlahnya, tanpa perasaan mendongkol, karena penerima yang patut akan mungkin ditemui yang menyelamatkannya dari segala dosa". (Manawadharmasastra IV.228). " waridastriptimapnoti sukha maksayyamannadah, 
tila pradah prajamistam dipadascaksur uttamam ",

artinya :

"Ia yang berderma air akan memperoleh kepuasan, berderma makanan akan memperoleh pahala kenikmatan, yang berderma biji-bijian akan memperoleh keturunan, dan yang berderma mampu akan memperoleh pengetahuan,yang sempurna”. (Manawadharmasastra IV. 229).

"bhumido bhumimapnoti dirgam ayurhiranyadah,

grihado'gryani wesmani rupyado rupam uttamam ",

artinya :

"Yang berderma tanah akan memperoleh dunia yang layak baginya, berderma emas memperoleh umur panjang, berderma rumah akan memperoleh karunia yang agung, yang berderma perak akan memperoleh keindahan”. (Manawadharmasastra IV. 230).

"wasodascandrasalokyam aswisalokyamaswadah,

anaduddah sriyam pustam godo bradhnasya wistapam "

artinya :

"Yang berderma pakaian akan memperoleh dunia yang layak di alam ini dan di bulan nanti, yang berderma kuda memperoleh kedudukan seperti dewa Asvina, yang berderma kerbau akan memperoleh keberuntungan dan yang berderma lembu akan mencapai suryaloka (Sorga)". (Manawadharmasastra IV. 231).

" yena yena tu bhawena yadyaddanam prayacchati,

tattattenaiwa bhawena prapnoti pratipujitah"

artinya :

“Apapun juga niatnya untuk berdana punia pahala itu akan diperolehnya di kemudian hari”. (Manawadharmasastra IV. 234).

" yo'rcitam pratigrihnati dadatyarcitamewa ca, tawubhau gacchatah swargam narakam tu wiparyaye " artinya :

"Ia yang dengan hormat menerima pemberian dana punia ia dengan tulus memberikannya keduanya mencapai sorga, dan apabila pemberian dan penerimaannya tidak tulus akan jatuh ke neraka”. (Manawadharmasastra IV. 235). 
Inilah keutamaan yadnya pada jaman Kali Yuga. Dengan melihat keadaan riil di saat sekarang ini dimana hal-hal yang natural atau alami sulit untuk didapatkan. Waktu mengikat kita dengan urusan-urusan duniawi, nilai-nilai kesadaran; kebenaran; kemanusiaan sudah jauh menurun. Kita menjadi asing dengan diri kita yang merupakan mahkluk sosial. Semua dapat tergantikan dengan materi, oleh sebab itu ajaran Hindu sudah menuliskan harus bagai mana kita melaksanakan kehidupan kita sebagai manusia. Agar tercapai tujuan tertinggi moksartham jagadhita ya ca iti dharma.

\section{DAFTAR PUSTAKA}

A. Drucker. 1991. Intisari Bhagawad Gita. Jakarta : Yayasan Sri Sathya Sai Indonesia G. Pudja, M.A. dan Tjokorda Rai Sudharta, M.A. 2004. Manavadharmasastra (Manu Dharmasastra). Surabaya : Paramita

Nyoman S. Pendit. 1993. Aspek-aspek Agama Hindu. Jakarta: Pustaka Manikgeni

Rama Navami. 1998. Intisari Ajaran Hindu. Surabaya : Paramita

http//www. Parisada Hindu Dharma Indonesia - Kewajiban Manusia Pada Zaman Kaliyuga.htm 

